\title{
Value of HRCT of the chest in evaluation of ankylosing spondylitis: correlation between pleuro-parenchymal abnormalities and disease activity
}

Iman Mohamed Hamdy Ibrahim, Ahlam Ahmed Hussein Alaqel ${ }^{1}$, Nehal El Ghobashy', Adel Ibrahim Azzam² and Mohammed Raafat Abd El-Mageed ${ }^{1 *}$ (D)

\begin{abstract}
Background: Ankylosing spondylitis (AS) is a chronic inflammatory disorder primarily involving the sacroiliac joints and spine. It is associated with both articular and extra-articular clinical manifestations. Pulmonary involvement is a well-recognized comorbidity of AS, even among patients with early disease. The availability of high-resolution computed tomography (HRCT) has enabled better visualization of the entire lung parenchyma and earlier identification of lung pathologies, ranging from mild to more severe involvement, which were previously missed on X-rays. The aim of the study is to establish the role of HRCT in the detection of pleuro-parenchymal manifestations of AS and to look for correlations between these findings and AS activity.
\end{abstract}

Results: Lung CT scans were done for all our patients and 27 patients (90\%) had positive HRCT thoracic findings, while the remaining 3 patients (10\%) had a normal HRCT thoracic study. Lower lobe fibrotic changes were the most common finding seen in 20 patients (66.7\%) followed by bronchial wall thickening in 13 patients (43.3\%) and upper and lower fibrotic changes seen in 9 patients (30\%). HRCT thoracic findings were more prominent in late AS (disease duration $\geq 10$ years) (13 of 13 patients); while 14 of 17 patients with early AS (disease duration $<10$ years) had mildly abnormal HRCT findings. The result of statistical analysis showed that there was negative correlation between thoracic findings and disease activity assessed by BASDAI and this correlation was insignificant ( $p$ value $=0.5$ ).

Conclusion: HRCT offers an accurate and safe method of assessment of lung disease in patients with AS and without respiratory symptoms. Although there was no correlation between pulmonary findings and AS activity assessed by BASDAl, a positive correlation, albeit insignificant, between pulmonary involvement and disease duration had been found.

Keywords: Ankylosing spondylitis, High resolution CT, Fibrosis, BASDAI score

\section{Background}

Ankylosing spondylitis is a chronic inflammatory disorder primarily involving the sacroiliac joints and spine. It is associated with both articular and extra-articular

\footnotetext{
*Correspondence: mohammed.raafat@kasralainy.edu.eg

${ }^{1}$ Faculty of Medicine, Cairo University, Giza, Egypt

Full list of author information is available at the end of the article
}

clinical manifestations, including peripheral arthritis, enthesitis, anterior uveitis, psoriasis, and inflammatory bowel disease. The first symptoms usually occur before the age of 30 and seldom occur after the age of 45 [1].

Pulmonary involvement is a well-recognized comorbidity of AS, even among patients with early disease. The availability of HRCT has enabled better visualization of the entire lung parenchyma and earlier identification 
of lung pathologies, ranging from mild to more severe involvement, which were previously missed on X-rays [2].

Pulmonary involvement encompasses a wide range of well-defined abnormalities including interstitial lung disease (ILD), upper lobe fibrosis, mycetoma formation as a result of secondary infections, emphysema, bronchiectasis, ventilatory impairment as a result of chest wall restriction and sleep apnea. Non-specific pleuropulmonary changes including, septal thickening, parenchymal micronodules, pleural thickening, parenchymal bands, bronchial wall thickening, and blebs have also been described $[3,4]$.

The aim of the study is to establish the role of HRCT in the detection of pleuro-parenchymal manifestations of AS and to look for correlations between these findings and AS activity.

\section{Methods}

This cross sectional study included 30 patients (26 males and 4 females), recruited from the outpatient clinic of Rheumatology and rehabilitation department in our institution from November 2018 to August 2019 according to the following criteria:

\section{Inclusion criteria}

Patients diagnosed as ankylosing spondylitis, according to the modified New York criteria [5] as relayed from records of inpatients in Rheumatology department.

\section{Exclusion criteria}

Patient with known associated chest diseases and nonimmune mediated pulmonary pathology e.g., old or active tuberculosis.

Patients with history of smoking.

All cases were subjected to the following:

- Informed written consent was obtained from all patients prior to enrollment.

- All data related to patients was collected and included: age, gender, duration of disease, history of smoking and tuberculous infection.

- Assessment of disease activity using Bath Ankylosing Spondylitis Disease Activity Index (BASDAI) [5]: The index consists of six questions. The responses were marked on a horizontal line measuring $10 \mathrm{~cm}$ (from 0 to $10 \mathrm{~cm}$ ), where the patient evaluates how he feels in relation to each item in the last week, marking on the scale: if the patient is fine ("very well"), he/she marks zero $\mathrm{cm}$, gradually increasing until "very poor", corresponding to a $10-\mathrm{cm}$ mark. The six questions comprising BASDAI are as follows: (1) How would you describe the degree of fatigue or tiredness you have had?; (2) How would you describe the overall level of neck, back and hip pain related to your illness?; (3) How would you describe the overall level of pain and edema (swelling) in other joints, apart from neck, back and hip?; (4) How would you describe the overall level of discomfort you felt to the touch or compression in the painful regions of your body?; (5) How would you describe the intensity of morning stiffness you have had, from the time you wake up?; (6) How long does your morning stiffness take, from the time you wake up?(

\section{Protocol for HRCT chest study}

All patients underwent scans at 16-MDCT scanner, Somatom, Emotion Siemens.

Patients were scanned in supine position in full inspiration. I.V. contrast wasn't administered.

After acquisition, acquired images were transferred to dedicated post-processing workstation where volumetric measurements were performed.

Scans were assessed by three radiologists of 20,10 and 3 years of experience. They were blinded to the clinical and laboratory data. Results were based on consensus agreement.

HRCT scans were evaluated for presence, distribution, and extent of HRCT abnormalities.

Standard CT criteria for ILD were used to establish ILD diagnosis by presence of its characteristic abnormalities (e.g., subpleural opacities, parenchymal bands, thickening interlobular septa, irregular pleural surface, honeycombing) and determining their extent and distribution pattern.

Multidetector high resolution CT protocols were applied with the patients in the dorsal decubitus position, during maximum inspiration, by using an 16-channel MDCT system. Contiguous axial slices of CT scans were obtained at $5 \mathrm{~mm}$ intervals, with $5 \mathrm{~mm}$ colimation, 130 Kvp, and an automatic tube modulation at $125 \mathrm{~mA}$. All images were obtained at window levels appropriate for lung parenchyma (window width $1000 \mathrm{HU}$; window level $-700 \mathrm{HU})$. Sagittal and coronal reconstructed images were performed.

\section{Statistical analysis}

Data was entered on the computer using "Microsoft Office Excel Software" program (2010) for windows. Data was then transferred to the Statistical Package of Social Science Software program, version 24 (IBM SPSS Statistics for Windows, Version 24.0. Armonk, NY: IBM Corp.) to be statistically analyzed.

Data presented using range, mean, standard deviation, median, quantitative variables, frequency, and percentage for qualitative ones. 
Pearson correlation coefficients were calculated to assess the association between disease duration, activity and presence of thoracic findings of AS.

$P$ values less than 0.05 were considered statistically significant.

\section{Results}

This cross-sectional study was conducted on 30 patients with AS, with 26 (86.7\%) males and 4 (13.3\%) females. The mean age of the patients was 37 , with the youngest being 17 years old and the oldest 59 years old. Mean disease duration was $8.9 \mathrm{y} \pm 4.9$ SD years with a range of from 1 to 20 years. In this study, we divided the patients into two groups according to disease duration of $\geq 10$ years (13 patients) and disease duration of less than 10 years (17 patents).

When evaluating the disease activity in AS patients using the BASDAI score (BASDAI 4 inactive diseases and BASDAI $\geq 4$ active diseases), mean score was $3.8 \pm 1.4$ SD, with 10 patients (33.3\%) had high disease activity and 20 patients $(66.7 \%)$ low disease activity.

Most of our study patients (17 patients) had no pulmonary symptoms. Among those who had symptoms, dyspnea on exertion was the most frequent finding (36.7\%), with other less frequent symptoms including mild dyspnea $(3.3 \%)$ and cough $(3.3 \%)$.

Lung CT scans were done for all our patients with 27 patients $(90 \%)$ had a positive HRCT thoracic finding (Table 1 ), while the remaining 3 patients $(10 \%)$ had a normal HRCT thoracic study.

Lower lobe fibrotic changes (fibrotic bands, parenchymal distortion and mild tractional bronchiectasis) were the most common finding seen in 20 patients (66.7\%) followed by bronchial wall thickening in 13 patients (43.3\%) and upper and lower fibrotic changes seen in 9 patients (30\%) (Figs. 1, 2, 3).

Interestingly, thoracic HRCT findings were more prominent in late AS (disease duration $\geq 10$ years) (13 of 13 patients); while 14 of 17 patients with early AS (disease duration $<10$ years) had abnormal HRCT findings (Table 1).

The result of statistical analysis showed that there was negative correlation between thoracic findings and disease activity assessed by BASDAI and this correlation was insignificant ( $p$ value $=0.5$ ).

Although, HRCT findings were more prominent in the late AS patients and all patients presenting with disease duration $\geq 10$ years had findings on HRCT, there was positive correlation between patients with thoracic findings and disease duration $=0.27$ but this correlation is insignificant $(p$ value $=0.2$ )
Table 1 Summary (frequency and percentage) of HRCT thoracic findings

\begin{tabular}{lcc}
\hline HRCT thoracic finding & Frequency & Percentage \\
\hline Summary of HRCT thoracic findings in our & & \\
study & 9 & 30.0 \\
Upper lobe fibrotic changes & 9 & 30.0 \\
Middle lobe fibrotic changes & 20 & 66.7 \\
Lower lobe fibrotic changes & 3 & 10.0 \\
Emphysema & 2 & 6.7 \\
Lung cysts & 13 & 43.3 \\
bronchial thickening & 6 & 20.0 \\
Lung nodules & 2 & 6.7 \\
Air trapping & 15 & 50.0 \\
Lung hyperlucency and hyperinflation & 0 & 0.0 \\
Pulmonary artery dilatation & 6 & 20.0 \\
Pleura thickening & 0 & 0.0 \\
Pleural effusion & 1 & 3.3 \\
Mild pericardial thickening & & \\
Other findings & 12 & 40 \\
Kyphosis & 23 & 76.6 \\
Facetal ankylosis & 7 & 23.3 \\
Squaring of vertebrae & 7 & 23.3 \\
Ligamentous ossification & 2 & 6.7 \\
Chalk stalk fracture & 9 & 30 \\
Fatty atrophy of back muscles & & \\
\hline
\end{tabular}

\section{Discussion}

Ankylosing spondylitis is a chronic and inflammatory disease that primarily affects the axial skeleton, the entheses and, less frequently, the peripheral joints. The most prevalent symptom of AS is chronic low back pain, and clinical manifestations usually include limited spinal range of motion, predominantly symmetric bilateral sacroiliitis on radiography, and positive serology for HLAB27 in $90-95 \%$ of cases [6].

Pleuropulmonary involvement was long considered as a rare and late manifestation of AS, because these lesions are usually asymptomatic and undetectable on chest radiographs in the early course of disease. Employing thoracic HRCT imaging, not only the classic lung lesion, but also a wide spectrum of subtle abnormalities, has been recently reported with a higher prevalence in patients with AS [7].

In the current study, majority of our AS patients (56.7\%) had no respiratory symptoms. The clinical symptoms of the remaining patients in descending order of frequency were dyspnea on exertion (36.7\%), mild dyspnea (3.3\%) and cough in (3.3\%). This is in accordance with Yuksekkaya et al. [3] who reported that nearly half 


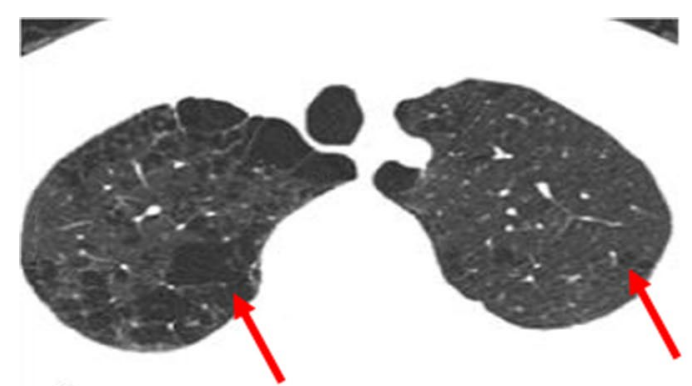

A
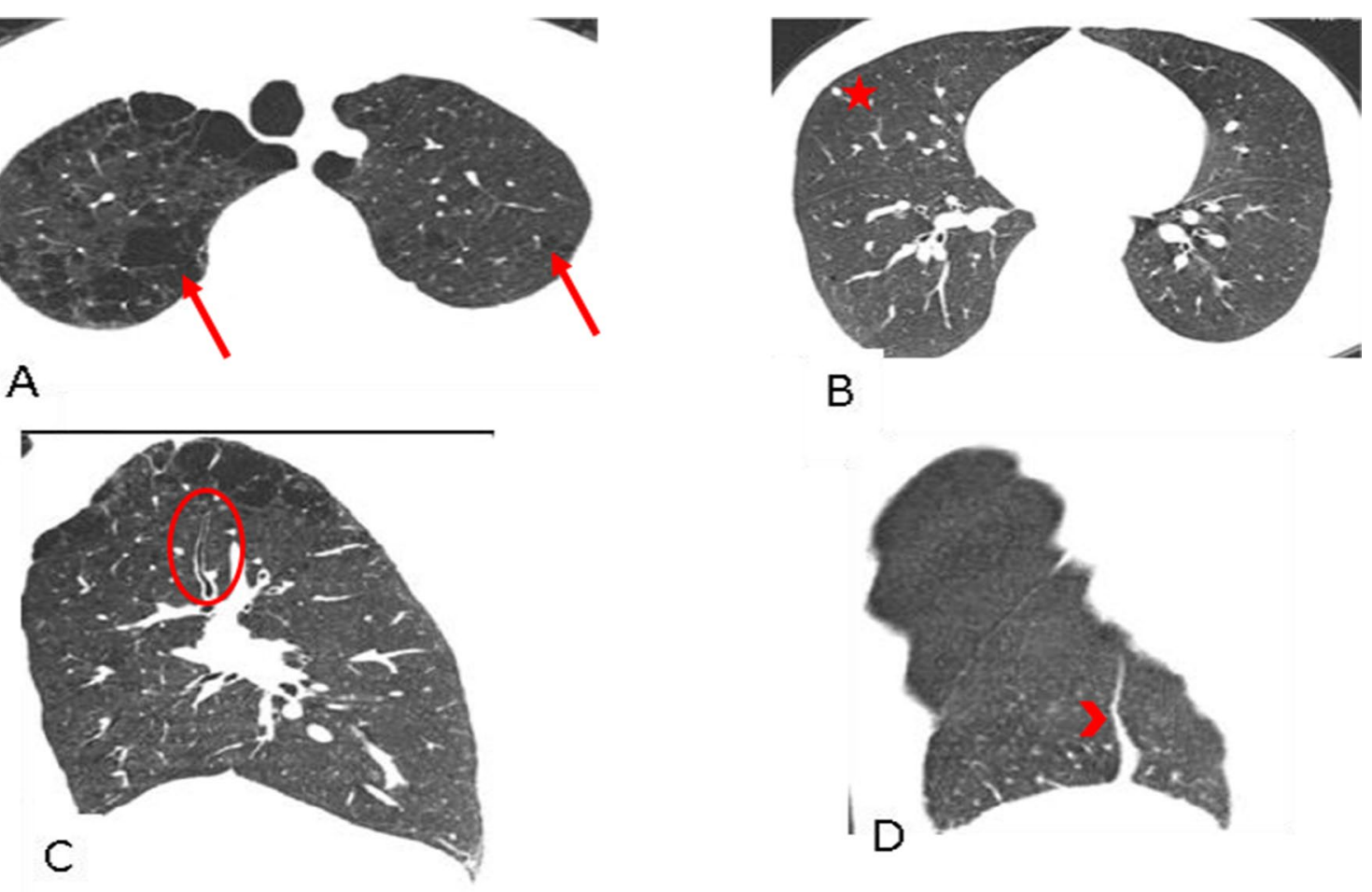

B

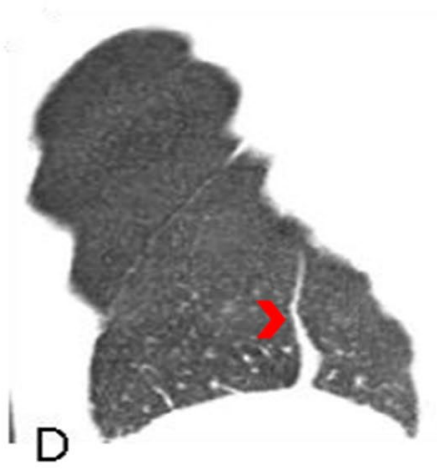

Fig. 1 a-c Axial HRCT of 33-year-old male (10 years disease duration) showing bilateral para-septal and centrilobular emphysema (arrows) (a), right middle lobe nodule (asterisk), hyperinflation, hyper-lucency (b). $\mathbf{c}, \mathbf{d}$ Sagittal reformatted HRCT image showing bronchial thickening (circle) (c) and lower lobe fibrotic changes (arrowhead) (d)

of their AS patients $(n=20 ; 48.8 \%)$ had no respiratory symptoms, while among those having symptoms cough was seen in 11 patients (26.8\%) and dyspnea in 11 others (26.8\%).

The HRCT findings in our study, as in the previous studies, would favor an inflammatory process rather than a mechanical etiology for the interstitial disease found in AS patients.

Twenty-seven (90\%) of AS patients in our study showed positive HRCT thoracic findings, but this percentage has varied in other studies. Our study result was close to the study done by Yuksekkaya et al. [3] who stated that $95.1 \%$ of patients had abnormal findings on CT. Again, Senocak et al. [8], using thoracic HRCT, found abnormalities in $17 / 20$ patients with AS.

On the other hand, our results were not inconsistent with the study done by Rezaei et al. [9] in which HRCT was performed in only $14(23.3 \%)$ patients, for ethical issues. Among these, 8 (57.1\%) patients had abnormality in HRCT.

Our study revealed that HRCT findings were more prominent in AS patients with disease duration $\geq 10$ years (13 of 13 patients), This was in consistent with Ozdemir et al. [7] in which abnormal HRCT findings was detected in $80 \%$ of patients with long disease duration $\geq 10$ years, and only in $40 \%$ in patients with disease duration of less than 10 years. In contrast to our study, Yuksekkaya et al. [3] concluded that thirty-one patients (96.87\%) with early AS and only 7 patients $(77.8 \%)$ with $\geq 10$ years disease duration had abnormal HRCT findings.

Our study revealed that the most frequent HRCT finding was lower lobe fibrotic changes (parenchymal bands) seen in two thirds of patients (66.7\%). Hasiloglu et al. [10] stated that the most common findings were parenchymal bands detected in 21 patients (27\%). In Sampaio-Barros et al. [11] as in the current study showed that nonspecific parenchymal opacities were the most frequent abnormalities. Of note, upper lobe fibrotic changes were less frequently detected as they were detected in 9 patients $(30 \%)$ and this not in line with Karakose Okyaltırik et al. [12] who stated that apical fibrosis was the most common HRCT abnormality.

The other frequently detected HRCT findings were lung hyper-lucency and hyperinflation $50 \%$, bronchial thickening $43.3 \%$ and pleural thickening $20 \%$. This in line with Souza et al. [13] which showed bronchial wall 


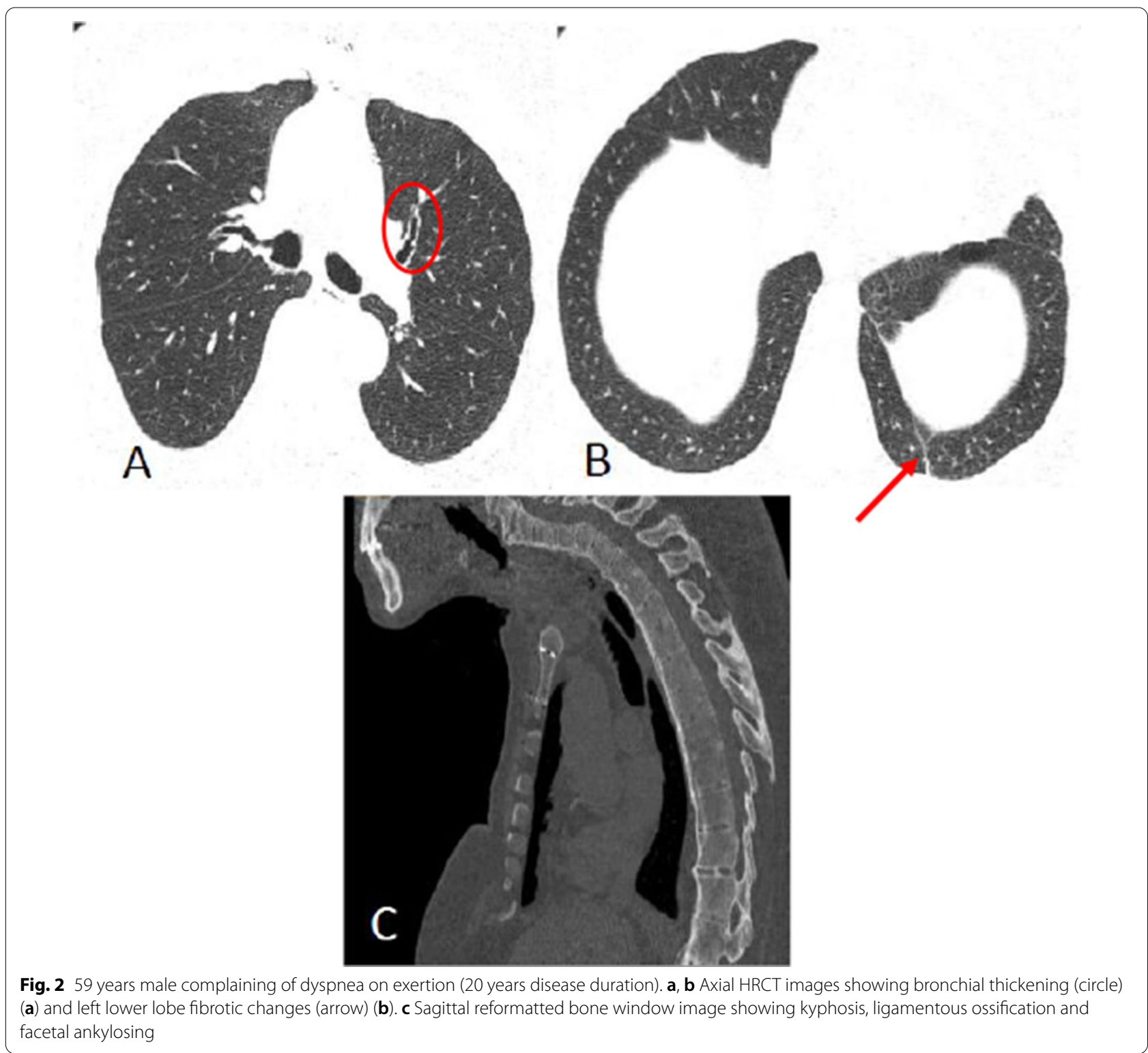

thickening in 7 (41\%). Yuksekkaya et al. [3] stated that peri-bronchial thickening $(n=29 ; 70.7 \%)$, pleural thickening $(n=24 ; 58.5 \%)$ were one of the most frequent abnormalities in their study which is more or less close to our result.

Lastly, in the present study we concluded that negative correlation between thoracic finding and disease activity assessed by BASDAI and this correlation is insignificant $p$ value $=0.5$, this was in concordance with Rezaei et al. [9] study which reported that no statistically significant relationship between disease activity and HRCT scan $(p=0.56)$ had been found.

A limitation of this study is the small population size, but this could be attributed to being a relatively rare disease.

\section{Conclusion}

HRCT offers an accurate and safe method of assessment of lung disease in patients with AS and without respiratory symptoms.

Including our results, the most common thoracic HRCT findings were lower lobe fibrotic changes, lung hyper-lucency and hyperinflation and bronchial thickening.

Although there was no correlation between pulmonary findings and AS activity assessed by BASDAI, a positive correlation, albeit insignificant, between pulmonary involvement and disease duration had been found. 


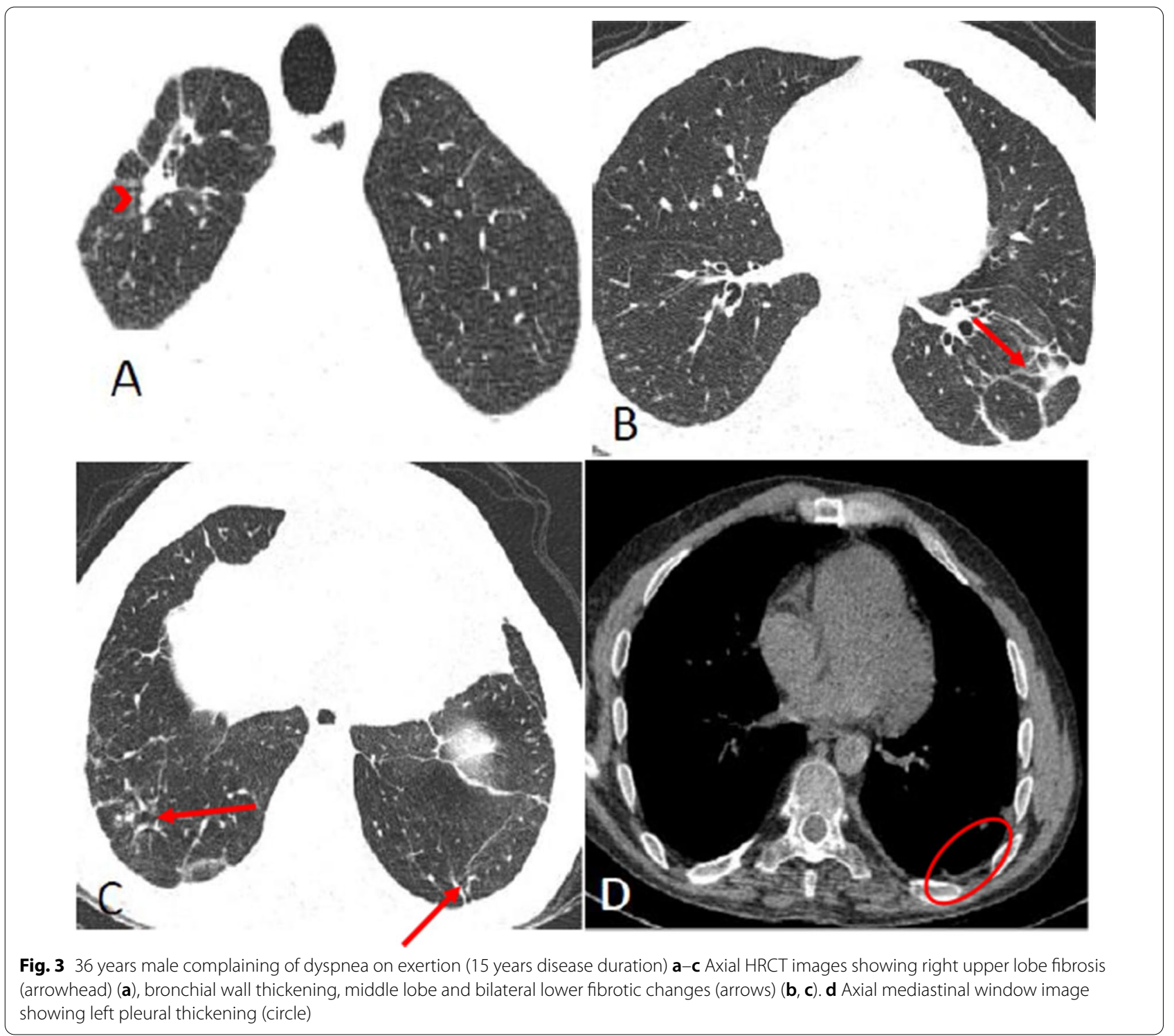

\section{Abbreviations}

AS: Ankylosing spondylitis; HCRT: High resolution computed tomography; BASDAl: Bath ankylosing spondylitis disease activity index; ILD: Interstitial lung disease; FOV: Field of view; kV: Kilovoltage; mA: Milliampere; WW: Window width; WL: Window level; SD: Standard deviation.

\section{Acknowledgements}

The authors would like to thank all the personnel contributed in this study.

\section{Authors' contributions}

IM and AA shared in study conception and design, processing CT findings and shared in writing and correcting the manuscript and revision. NE shared in study conception and design, collecting patient's data, analysis and interpretation of data. Al shared in study conception and design, analysis and interpretation of data and drafting of manuscript. MR shared in study conception and design, acquisition of data, analysis and interpretation of data and drafting of manuscript. All authors read and approved the final manuscript.

\section{Funding}

This study had no funding from any resource.

\section{Availability of data and materials}

The datasets used and/or analyzed during the study are available upon reasonable request.

\section{Declarations}

\section{Ethics approval and consent to participate}

No individual data included in the study. This study was approved by the Research Ethics Committee of the Faculty of Medicine at Cairo University Kasr El-Aini in Egypt in October 2019; reference number I-120818 All patients included in this study gave verbal informed consent to participate in this research. If the patient was unconscious at the time of the study, written informed consent for their participation was given by their legal guardian.

\section{Consent for publication}

All patients included in this study gave written informed consent to publish the data contained within this study. If the patient was unconscious when consent for publication was requested, written informed consent for the publication was given by their legal guardian. 


\section{Competing interests}

The authors declare that they have no competing interests.

\section{Author details}

${ }^{1}$ Faculty of Medicine, Cairo University, Giza, Egypt. ${ }^{2}$ Faculty of Medicine, Azhar University, Cairo, Egypt.

Received: 10 July 2021 Accepted: 2 September 2021

Published online: 27 October 2021

\section{References}

1. Exarchou S, Lindström U, Askling J, Eriksson JK, Forsblad-Elia H, Neovius M et al (2015) The prevalence of clinically diagnosed ankylosing spondylitis and its clinical manifestations: a nationwide register study. Arthritis Res Ther 17(1):118

2. Mercieca C, van der Horst-Bruinsma IE, Borg AA (2014) Pulmonary, renal and neurological comorbidities in patients with ankylosing spondylitis; implications for clinical practice. Curr Rheumatol Rep 16(8):434

3. Yuksekkaya R, Almus F, Celıkyay F, Celıkel S, Inanır A, Almus E, Ozmen Z (2014) Pulmonary involvement in ankylosing spondylitis assessed by multidetector computed tomography. Pol J Radiol 79:156

4. El Maghraoui A, Chaouir S, Abid A, Bezza A, Tabache F, Achemlal L et a (2004) Lung findings on thoracic high-resolution computed tomography in patients with ankylosing spondylitis. Correlations with disease duration, clinical findings and pulmonary function testing. Clin Rheumatol 23(2):123-128

5. Gossec $L$ (2018) Monitoring of disease and treatment of patients with rheumatic disease, 97-125. https://doi.org/10.1016/B978-0-444-63887-8. 00005-0

6. Ng SC, Liao Z, Yu DTT, Chan ESY, Zhao L, Gu J (2007) Epidemiology of spondyloarthritis in the People's Republic of China: review of the literature and commentary. In: Seminars in arthritis and rheumatism. Elsevier

7. Özdemir O, Akpınar MG, İnanıcı F, Hasçelik HZ (2012) Pulmonary abnormalities on high-resolution computed tomography in ankylosing spondylitis: relationship to disease duration and pulmonary function testing. Rheumatol Int 32(7):2031-2036https://doi.org/10.12659/pjr.889850

8. Senocak O, Manisaly M, Ozaksoy D, Sevinc C, Akalyn E (2003) Lung parenchyma changes in ankylosing spondylitis: demonstration with high resolution CT and correlation with disease duration. Eur J Radiol 45:117-122

9. Rezaie N, Almasi S, Zamani K (2018) The prevalence and type of pulmonary involvement in ankylosing spondylitis. Rheumatol Res 3(2):59-62

10. Hasiloglu ZI, Havan N, Rezvani A, Sariyildiz MA, Erdemli HE, Karacan I (2012) Lung parenchymal changes in patients with ankylosing spondylitis. World J Radiol 4(5):215

11. Sampaio-Barros PD, Cerqueira EMF, Rezende SM, Maeda L, Conde RA, Zanardi VA et al (2007) Pulmonary involvement in ankylosing spondylitis. Clin Rheumatol 26(2):225-230

12. Karakose Okyaltırık F, Rezvani A, Turan S, Uysal Ö, Yakar F, Sozgen H, Ozkan NE, Akkoyunlu ME, Bayram M, Kutbay Ozcelik H, Sezer M, Guler M, Yaylım I, Kart L (2017) Relationship of CTLA4 and CD28 polymorphisms with lung involvement, HRCT findings and pulmonary function tests in Turkish patients with ankylosing spondylitis. Clin Respir J 5:593-601

13. Souza AS Jr, Müller NL, Marchiori E, Soares-Souza LV, de Souza Rocha M (2004) Pulmonary abnormalities in ankylosing spondilitis: inspiratory and expiratory high-resolution CT findings in 17 patients. J Thorac Imaging 19(4):259-263

\section{Publisher's Note}

Springer Nature remains neutral with regard to jurisdictional claims in published maps and institutional affiliations.

\section{Submit your manuscript to a SpringerOpen ${ }^{\circ}$ journal and benefit from:}

- Convenient online submission

- Rigorous peer review

- Open access: articles freely available online

- High visibility within the field

- Retaining the copyright to your article

Submit your next manuscript at $\boldsymbol{\nabla}$ springeropen.com 